\title{
Neonatal spectral EEG is prognostic of cognitive abilities at school age in premature infants without overt brain damage
}

\author{
Elisa Cainelli ${ }^{1,2} \cdot$ Luca Vedovelli $^{3} \cdot$ Isabella Lucia Chiara Mariani Wigley ${ }^{4}$ Patrizia Silvia Bisiacchi ${ }^{1,5} \cdot$ Agnese Suppiej $^{2,6}$
}

Received: 10 August 2020 / Revised: 16 September 2020 / Accepted: 21 September 2020 / Published online: 29 September 2020

(C) The Author(s) 2020

\begin{abstract} attention tests. The performance on the same tests appears to be mainly impaired. on ongoing development, pointing to the importance of early prognostic instruments.

\section{What is Known:}

- Prematurity is a non-specific marker of late neurocognitive risk.

- Precise prognostic instruments are lacking, mostly in patients with low-grade conditions.

What is New:

- Longitudinal long-term studies are scarce but crucial for the inferential attributive process.

- Spectral EEG frequencies are independent predictors of performance in attention tasks.
\end{abstract}

Prematurity is a prototype of biological risk that could affect the late neurocognitive outcome; however, the condition itself remains a non-specific marker. This longitudinal 6-year study aimed to evaluate the prognostic role of neonatal spectral EEG in premature infants without neurological complications. The study cohort was 26 children born 23-34 gestational ages; all neonates underwent multichannel EEG recordings at 35 weeks post-conception. EEG data were transformed into the frequency domain and divided into delta $(0.5-4 \mathrm{~Hz})$, theta $(5-7 \mathrm{~Hz})$, alpha $(8-13 \mathrm{~Hz})$, and beta $(14-20 \mathrm{~Hz})$ frequency bands. At 6 years, a neuropsychological and behavioral evaluation was performed. Correlations between spectral bands and neuropsychological assessments were performed with a conservative and robust Bayesian correlation model using weakly informative priors. The correlation of neuropsychological tasks to spectral frequency bands highlighted a significant association with visual and auditory

Conclusions: We found that spectral EEG frequencies are independent predictors of performance in attention tasks. We hypothesized that spectral EEG might reflect early circuitries' imbalance in the reticular ascending system and cumulative effect

Elisa Cainelli and Luca Vedovelli contributed equally to the work.

Communicated by Daniele De Luca

Electronic supplementary material The online version of this article (https://doi.org/10.1007/s00431-020-03818-x) contains supplementary material, which is available to authorized users.

Patrizia Silvia Bisiacchi

patrizia.bisiacchi@unipd.it

Elisa Cainelli

elisa.cainelli@unipd.it

Luca Vedovelli

luca.vedovelli@unipd.it

Isabella Lucia Chiara Mariani Wigley

isabellaluciachiara.marianiwigley@phd.unipd.it

Agnese Suppiej

Agnese.suppiej@unife.it
1 Department of General Psychology, University of Padova, via Venezia 8, 35131 Padova, Italy

2 Child Neurology and Clinical Neurophysiology, Padua University Hospital, via Giustiniani 3, 35133 Padova, Italy

3 Lab LeSexp, Unit of Biostatistics, Epidemiology, and Public Health, Department of Cardiac, Thoracic, Vascular Sciences, and Public Health, University of Padova, via Loredan 18, 35131 Padova, Italy

4 Department of Developmental and Social Psychology, University of Padova, via Venezia 8, 35131 Padova, Italy

5 Padova Neuroscience Centre, PNC, Padova, Italy

6 Department of Medical Sciences, Pediatric Section, University of Ferrara, via Aldo Moro 8, 44124 Cona, Fe, Italy 
Keywords Neonate $\cdot$ Reticular activating system $\cdot$ Arousal-attentional system $\cdot$ Quantitative EEG $\cdot$ Long-term outcome $\cdot$ Preterm birth

$\begin{array}{ll}\text { Abbreviations } \\ \text { ADHD } & \text { Attention/hyperactivity disorder } \\ \text { CGI } & \text { Conners global index } \\ \text { CRS-R } & \text { Conners' Rating Scales-Revised } \\ \text { EEG } & \text { Electroencephalogram } \\ \text { HMC } & \text { Hamiltonian Monte Carlo } \\ \text { VMI } & \text { Visual-motor integration } \\ \text { WPPSI-III } & \text { Wechsler Preschool and Primary } \\ & \text { Scale of Intelligence III } \\ \text { WISC-IV } & \text { Wechsler Intelligence Scale for Children IV }\end{array}$

\section{Introduction}

Long-term neurodevelopmental impairments remain a major concern after premature birth, particularly in infants born at the lowest gestational ages [1-3]. Prematurity is a prototype of biological risk that could affect the neurocognitive outcome; however, it remains a non-specific marker [4]. It may negatively affect the normal maturational processes also in infants without overt brain damage or medical complications [5, 6]. Thus, even apparently healthy children, who did not develop major sequelae in the first years of life, are at risk for neurocognitive impairments emerging at older ages, typically during the school period $[7,8]$. Deficits are reported in visualmotor [9, 10], linguistic [11], attention and executive functions [12], and learning and achievements [13-15]. Furthermore, children may manifest behavioral and psychological problems [16].

Abnormalities in high-order neuropsychological functions require many years to manifest [17-19], due to the slow rate of maturation of complex abilities such as attention and executive functions. Abnormalities in circuitry formation begin early but will manifest only when the system is no longer able to compensate for the constantly increasing demands of the surrounding environment. The first years of age are characterized by a high plasticity, but, once consolidated, the altered pattern of functioning may become a stable characteristic, as shown by studies on long-term follow-up in the adolescence and adulthood [16, 20].

Although not so disabling compared with cerebral palsy and intellectual disability, long-term neuropsychological and behavioral impairments affect the life quality of children and their families. Their incidence is growing [21], and school and sanitary services are increasingly overloaded. The early identification of children at risk is hampered by the scarcity of good neonatal markers, mainly when the perinatal period runs without medical complications or signs of brain damage.
Several functional neuroimaging studies highlighted abnormalities in premature brain functioning even in the absence of overt brain damage [1, 22-24]. The electrophysiological tools have the advantage over imaging techniques of being less expensive and available at the bedside. Abnormal developmental trajectories of early prematurity could be detected as early as 35 weeks post-conception, both using event-related potentials [25-27] and quantitative EEG [28-30].

Power spectral analysis is a simple, objective, and sensitive method for quantifying the digitized EEG.

The prognostic value of spectral EEG analysis on longterm sequelae is yet scarcely investigated. Still, the few available literature data suggest good prognostic abilities [31], also in children born prematurely [32]. Long-term longitudinal studies are crucial in developmental cognitive neuroscience, for the inferential attributive process and in the understanding of early developmental trajectories. Their use is limited by the need for covering the years elapsing from the neonatal period to the age when complex cognitive functions develop and can be tested.

This prospective longitudinal 6-year study aimed to evaluate the prognostic role of spectral EEG recorded at 35 weeks post-conception in premature infants free of medical and neurological complications, attaining school age. Thirty-fiveweek gestation is a critical time of brain maturation [33], and neurophysiological testing close to this period, rather than 40 post-conception, might highlight subtle and/or transient abnormalities before the compensation mechanisms occur, and could have a role in long-term prognosis.

\section{Methods}

\section{Participants}

The study cohort was a subset of 26 children born between January 2011 and January 2012, recruited from our ongoing prospective study on perinatal risk factors and long-term outcomes of neonates admitted to the neonatal intensive care unit.

Inclusion criteria for the present study were gestational age at birth lower than 35 weeks, having successfully performed a neonatal multichannel EEG of at least 1-h duration at a corrected age of 35 weeks, written consent of the parents to the study, and adherence to all the follow-up.

Exclusion criteria were neonatal neurological risk factors as detailed elsewhere [28]. Briefly, neonates were recruited when none of the following neurological risk factors was present: intrauterine growth restriction (defined as an estimated fetal weight below the 10th percentile and umbilical artery 
pulsatility index greater than 2 standard deviations), craniofacial malformations, clinical evidence of neonatal encephalopathy, brain ultrasound evidence of intra-ventricular hemorrhage or periventricular cystic leukomalacia, occurrence of seizures, treatment with drugs (e.g., sedatives) affecting the central nervous system. Furthermore, we excluded children with abnormal EEG traces as evaluated by visual inspection, a post-neonatal diagnosis of genetic, metabolic or neurodegenerative syndrome or intellectual disability, cerebral palsy, sensorial invalidating deficits, epilepsy, at any time during the follow-up period. Seventeen patients out of the total cohort of 26 patients were part of a previous study reporting the outcome at 1 year of age [28].

The patient's clinical characteristics are reported in Table 1.

All procedures contributing to this work comply with the ethical standards of the relevant national and institutional committees on human experimentation and with the Helsinki Declaration of 1975, as revised in 2008. The Institutional Ethical Committee approved the study (Comitato Etico per la Sperimentazione Clinica dell'Azienda Ospedaliera di Padova, Prot. N. 1693P).

\section{Neonatal neurophysiological assessment}

Recordings were performed before discharge from the hospital when infants were clinically stable. Post-conceptional age was computed as the sum of gestational age at birth, and the period of extra-uterine life elapsed from birth to the day of EEG recording [34].

The methodology for EEG recording was previously detailed [28].

In brief, electrodes were placed according to the 10-20 International System of electrode placement and international guidelines for neonates. We used a Galileo EEG system (EB Neuro, Florence, Italy). We choose to analyze EEG segments recorded in active sleep because this state represents predominantly neocortical activity [35]. We considered for spectral analysis, only EEG segments where both EEG and behavioral evaluation confirmed an active sleep stage. For offline

Table 1 Clinical data of the children recruited for the study

\begin{tabular}{lc}
\hline GA mean (range) & $29.5(23-34)$ \\
Birth weight $(\mathrm{g})$ & $1350 \pm 391$ \\
Birth length $(\mathrm{cm})$ & $37.6 \pm 4.4$ \\
Birth CC $(\mathrm{cm})$ & $28.4 \pm 3.5$ \\
Male rate & $16(61.5 \%)$ \\
$1^{\circ}$-min Apgar score & $6.8 \pm 1.6$ \\
$5^{\circ}$-min Apgar score & $8.2 \pm 0.97$ \\
pH at birth & $7.25 \pm 0.12$ \\
\hline
\end{tabular}

$G A$, gestational age; $P C A$, post-conceptional age; $C C$, cranial circumference analysis, $30 \mathrm{~min}$ of artifact-free EEG traces were selected from at least $1-\mathrm{h}$ recording.

\section{Data analysis}

Pre-processing and spectral analysis were performed as previously described [28] using the EEGLAB toolbox and a custom-scripted software in the MATLAB environment. In brief, the frequency spectrum was divided into the following bands: delta $(0.5-4 \mathrm{~Hz})$, theta $(5-7 \mathrm{~Hz})$, alpha $(8-13 \mathrm{~Hz})$, beta $(14-20 \mathrm{~Hz})$. Absolute power (defined as the integral of all powers within the frequency band, expressed in $\mu \mathrm{V}^{2}$ ) was calculated from the transformed signal. As the total absolute spectral power may vary considerably, spectral values among subjects were normalized for total power and expressed as relative spectral power measures (defined as the ratio of absolute band power and total power of all bands, expressed in percentage).

Finally, we calculated the main total spectral power for the delta, theta, alpha, and beta bands by performing the mean of $\mathrm{Fz}, \mathrm{C} 3, \mathrm{Cz}, \mathrm{C} 4, \mathrm{~T} 3$, and T4 locations activity. The Fp1, Fp2, $\mathrm{O} 1$, and $\mathrm{O} 2$ locations were excluded because of the numerous artifacts on these channels.

An example of the processing of EEG tracing in the frequency spectrum is reported in Fig. 1 (panels A and B).

\section{Follow-up neuropsychological assessment}

Neuropsychological assessment was conducted by a psychologist trained in test administration and scoring (E.C.) at the mean age of 6 years (SD 0.45).

Cognitive assessment We used the Wechsler Preschool and Primary Scale of Intelligence III (WPPSI-III) test or the Wechsler Intelligence Scale for Children IV (WISC-IV), standardized for Italian sample, to evaluate general cognitive performance [36-38]. All results were expressed as an agestandardized score, with a population means of 100 and a standard deviation of 15 .

Neuropsychological testing The following cognitive domains were assessed: language, using the naming test and the semantic verbal fluency test, which evaluates the ability to access the lexicon through a categorial cue [39]; attention, using the visual and auditory attention tests of the NEPSY-II [40, 41]; memory, using the Corsi block-tapping test, which evaluates short-term verbal and visuo-spatial memory, and the word's list and list recall, which evaluate learning and long-term verbal memory [39]; executive functions, using the Tower of London test, which evaluates planning and problem-solving [42], the Coding test of the WISC-IV or WPPSI-III [37, 38], the Stroop Test, which evaluates inhibitory control [43]; visuo-motor functions, using the visual-motor integration 


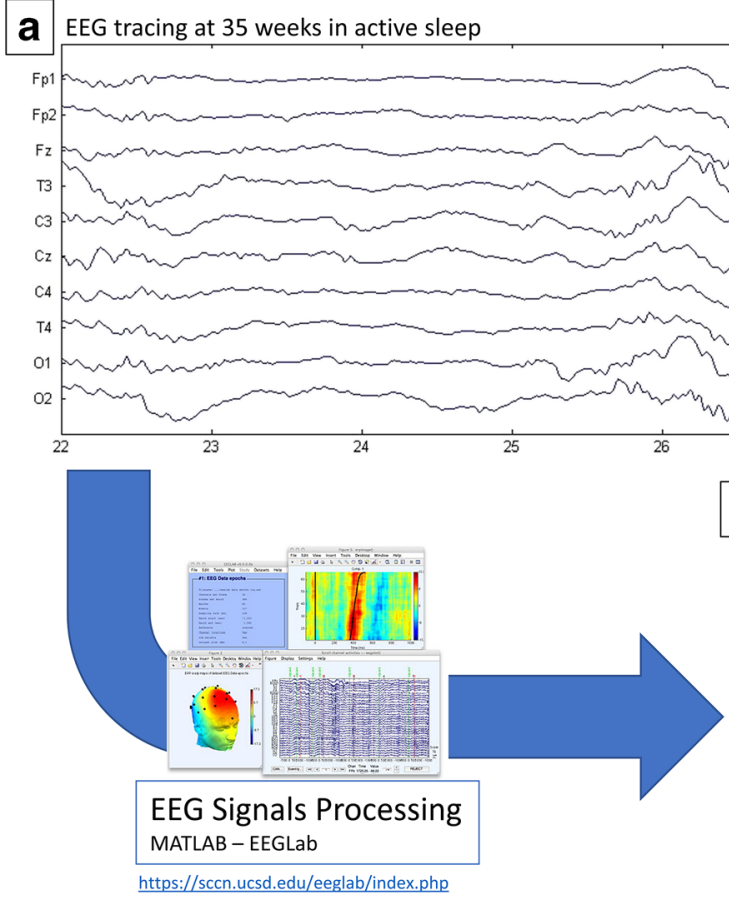

Fig. 1 The processing procedure of transformation the EEG tracing (panel A) of one neonate at 35 weeks post-conception in active sleep in the frequency spectrum (panel B). Panel C shows the EEG power spectra

(VMI, [44]); social skills, using the Theory of Mind and the Emotional recognition tests of the NEPSY-II [40, 41]. The entire test battery required nearly $3 \mathrm{~h}$, divided into two meetings, to be completed.

We administered to the parents the questionnaire Conners' Rating Scales-Revised (CRS-R) in order to identify the presence of behavioral problems and ADHD. The Conners Parent Rating Scales-long version (CPRS-R:L) report parent ratings of child behaviors involving problems in seven psychopathological areas: oppositional, inattention, hyperactive, anxiousshy, perfectionism, social problems, and psycho-somatic. For the analysis, total scores were considered: the ADHD total score, the CGI (Conners global index) total score, and DSMIV total score [45].

\section{Statistical analysis}

Continuous variables were tested for normality and summarized as mean and standard scores. Scores for the cognitive, neuropsychological, and questionnaires were age-corrected and converted into $z$ scores and scaled scores (neuropsychological tests), $T$ scores (questionnaires), or standard scores (cognitive tests), based on published normative data. The $z$ scores indicate the deviation from the mean population score, which is set to 0 , standard deviation 1 . A $z$ score of -2 (or less) comprised $2.5 \%$ of the normal distribution and was considered to be significantly lower than average. Scaled scores indicate the deviation from the mean population score, which

\section{0-channel EEG}

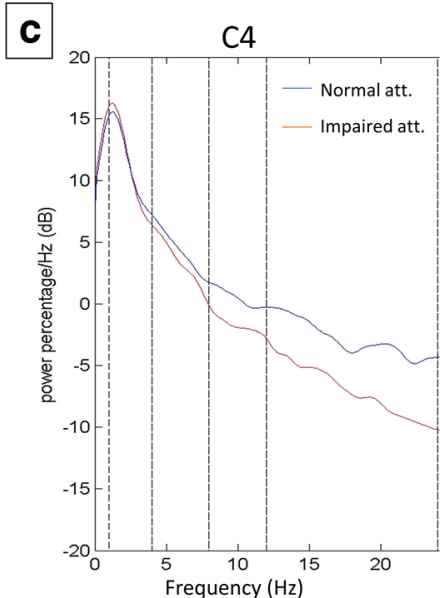

at 35 post-conception on $\mathrm{C} 3$ channel of children with impaired and normal performance to the visual attention task

was set to 10 , standard deviation 3. A scaled score of 4 (or less) was considered to be significantly lower than average. The $T$ scores indicate the deviation from the mean population score, which was set to 50, standard deviation 10. A $T$ score of 70 (or more) indicates a clinical condition.

Results of the WPPSI-III and of the WISC-IV have been converted in standard scores having mean 100 and standard deviation 15. Impairment was defined as a standard score lying two standard deviations below the mean $(<70)$.

We evaluated the direct correlations between neuropsychological and EEG spectral data using a regression model robust to outliers with bivariate Student's $t$ distribution [46]. We performed the analysis in a Bayesian framework to avoid arbitrary multiple-comparisons corrections and to minimize false discovery rates by imposing weakly informative priors on the model's parameters $[47,48]$. Specifically, we used LKJ prior distribution [49] on the correlation's parameters with the concentration parameter equal to 4. Such prior distribution, highly concentrated around zero, minimizes the risk of observing non-null correlations, which may arise only by random chance, as it often occurs in small sample size settings, like in our study. Significant correlations were identified as those whose posterior intervals do not contain the zero value, i.e., the value of no correlation. The sampling from the posterior distribution of the model's parameters was carried out using the Hamiltonian Monte Carlo (HMC) algorithm with Stan software for Bayesian inference [50]. The algorithm was run with four chains and 2000 iterations, of which 500 
were discarded as warm-up. The convergence of the algorithm was assessed using trace plots and an improved version of the R-hat [51].

We implemented the statistical analysis in R software for statistical computing [52] (version 3.6.2). The brms package was used to fit the models (version 2.11.1) [53]. The full $\mathrm{R}$ code of the model is available in the supplementary materials.

\section{Results}

Mean scores were in the range of normality for all the cognitive and neuropsychological domains explored (Table 2).

The Bayesian correlation model converges for all the analyzed pairs of variables.

By considering individual impairments in cognitive and neuropsychological tests, six children exhibited a borderline cognitive profile $(70>$ IQ $<85$ ); eight showed at least two neuropsychological impaired tests $(<2$ standard deviations). By considering individual impairments on total scores of CPRS-L questionnaire, five children obtained a borderline score in the ADHD total score, one child a borderline score in CGI total score, and finally, four impaired sores in the DSM-IV total score.

The correlation of neuropsychological tasks to spectral frequency bands highlighted a significant association with visual and auditory attention tests (Table 3). Figure 1 (panel C) shows the EEG power spectra at 35 post-conception on $\mathrm{C} 3$ channel of children with impaired and normal performance to the visual attention task.

Table 2 Mean and standard deviation scores of cognitive and neuropsychological tasks

\begin{tabular}{llc}
\hline Domain & Test & Mean \pm SD \\
\hline General intelligence & IQ & $96.6 \pm 20.5$ \\
Language & Semantic fluency $(z$ scores) & $-0.86 \pm 0.56$ \\
& Naming ( $z$ scores) & $-0.21 \pm 0.48$ \\
Memory & Corsi ( $z$ scores) & $0.14 \pm 0.68$ \\
& Word's list $(z$ scores) & $0.26 \pm 0.91$ \\
& List recall $(z$ scores) & $0.09 \pm 2.47$ \\
Visual-motor & VMI (SS) & $10.8 \pm 0.0$ \\
abilities & & \\
Executive functions & TOL ( $z$ scores) & $-0.42 \pm 0.12$ \\
& Stroop ( $n, \%$ impaired) & $2(7 \%)$ \\
Attention & Coding (SS) & $7.64 \pm 6.36$ \\
& Visual attention (SS) & $10.8 \pm 1.41$ \\
Social skills & Auditory attention $(n, \%$ impaired) & $7(27 \%)$ \\
& Mind's theory total (SS) & $8.45 \pm 2.82$ \\
& Emotional recognition (SS) & $7.65 \pm 5.65$ \\
\hline
\end{tabular}

$S D$, standard deviation; $I Q$, intelligence quotient; $V M I$, visual-motor integration test; $S S$, scaled scores; TOL, Tower of London
Table 3 Non-zero correlations from the Bayesian model

\begin{tabular}{ll}
\hline Parameters & $\begin{array}{l}\text { Correlation coeff. } \\
\text { Median (95\% C.I. })\end{array}$ \\
\hline Visual attention vs. TOT alpha & $0.46(0.10-0.71)$ \\
Visual attention vs. Cz alpha & $0.41(0.05-0.68)$ \\
Visual attention vs. C4 alpha & $0.41(0.07-0.67)$ \\
Visual attention vs. T4 alpha & $0.42(0.07-0.68)$ \\
Visual attention vs. O2 alpha & $0.37(0.01-0.64)$ \\
Visual attention vs. TOT beta & $0.52(0.17-0.76)$ \\
Visual attention vs. C4 beta & $0.45(0.10-0.71)$ \\
Visual attention vs. T4 beta & $0.47(0.11-0.72)$ \\
Visual attention vs. T3 beta & $0.40(0.05-0.66)$ \\
Visual attention vs. O2 beta & $0.43(0.06-0.68)$ \\
Visual attention vs. TOT beta & $0.52(0.17-0.76)$ \\
Auditory attention vs. T4 alpha & $0.40(0.04-0.66)$ \\
\hline
\end{tabular}

The same tests appear to be mainly impaired ( 7 children with deficits in auditory attention, 6 in visual attention).

Scatterplots of performance to visual attention test and spectral values are shown in Fig. 2.

\section{Discussion}

In the present study, we evaluated the prognostic role of spectral analysis of the EEG in those infants without medical complications. They are the most challenging group of premature infants because the prognosis is particularly tricky, and gestational age remains the unique indicator of risk.

We recorded the EEG in a crucial phase of brain development when first cortical circuitries start to develop [54]; the outcome was measured 6 years after the perinatal period, at another crucial phase of development, the school period. Outcome measures included both neuropsychological tests able to detect subtle deficits in cognition and parent's questionnaire on child behavior.

We found that spectral EEG frequencies are independent predictors of performance in attention tasks, both in the visual and the auditory modality. In contrast, we did not found any correlations with other tasks or questionnaires and, interestingly, with gestational age.

Neonatal EEG of children performing worse to attention tasks had a relatively lower amount of power in the alpha and beta bands.

In the immature brain, the slow activity (i.e., in delta range) is the predominant feature of the background EEG [30]. It has an established role in the functional and structural shaping of neuronal circuitries [55]. By contrast, the higher frequencies are physiologically underrepresented before the beginning of the cerebral cortex maturation and progressively emerge 
Fig. 2 Scatterplots of performance to the visual attention task in the total delta, theta, alpha, and beta bands (raw data)
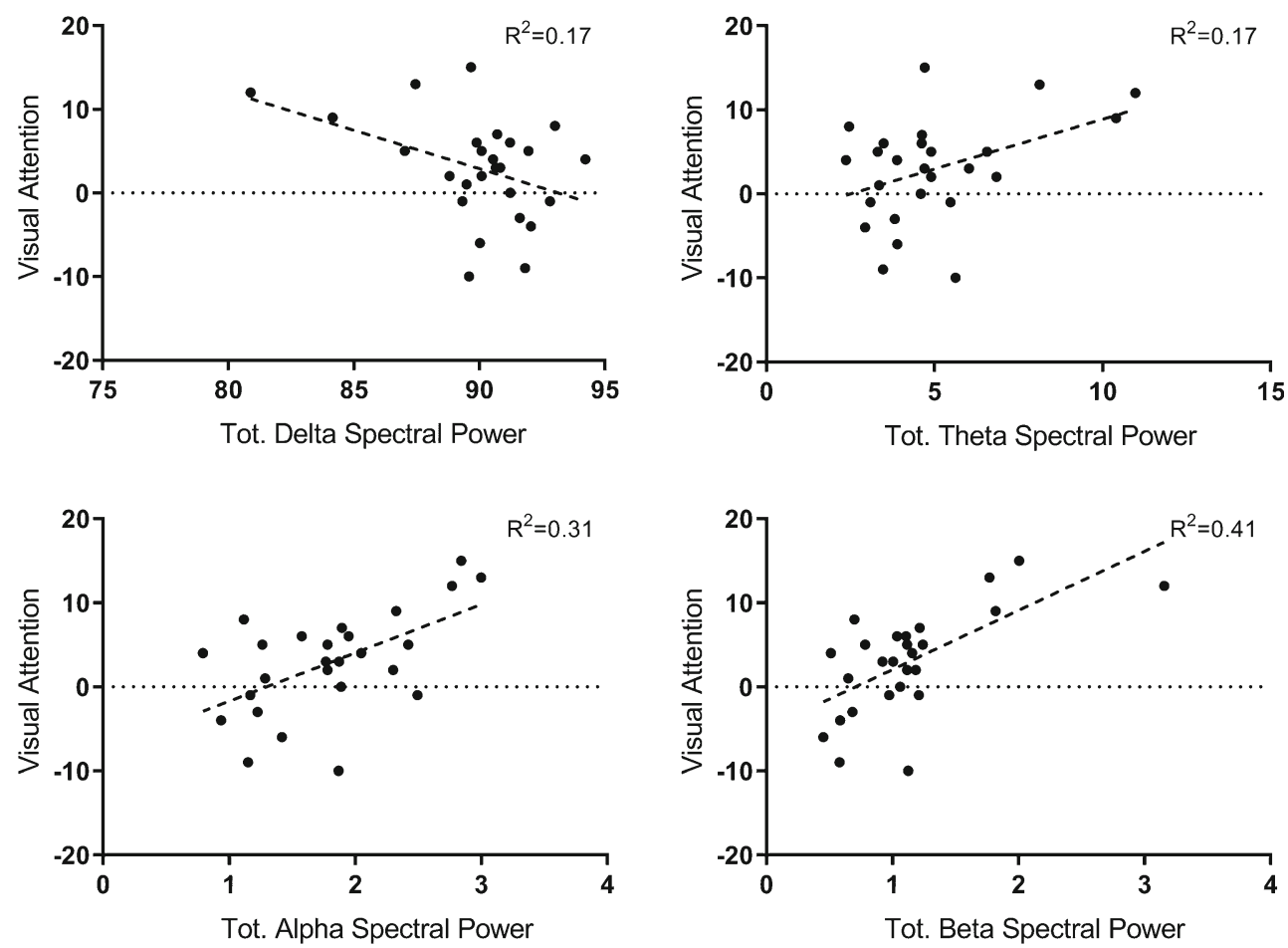

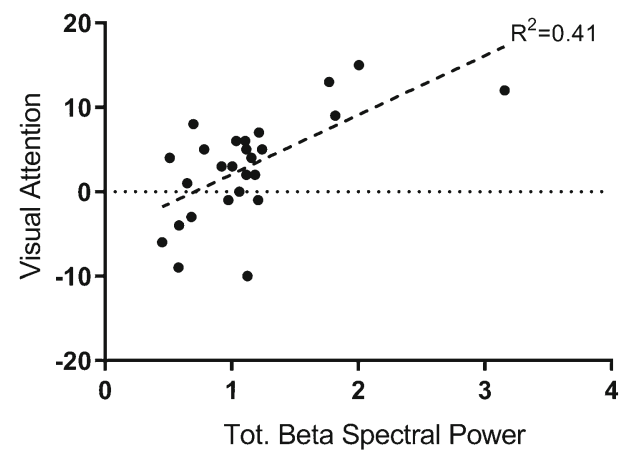

during the last trimester of pregnancy, around 34-35 weeks of gestation [56, 57]. In fact, thirty-five-week gestation is a critical time of brain maturation: EEG background activity becomes continuous, cortical evoked potentials change from prevalent negative to positive polarity, and spectral power analysis shows increased high-frequency content [54]. These changes are due to the major development of cerebral pathways and transient organization of both neuronal circuitry and fetal brain lamination [33].

Evaluation of the emergence and characterization of spectral EEG components and their deviation from the expected typical trajectory may be important to understand early abnormalities of brain development. In a previous study, we showed, at 35 weeks post-conception, a preponderant slow and high-voltage activity in premature infants born at extremely low gestational age [28]. We speculated that an imbalance between low- and high-frequency EEG content could reflect a failure of the early developmental trajectory of the cerebral organization since it was associated with worse neurodevelopmental scores at 1 year. With the present study, we prolonged the follow-up until 6 years of age on a broader population, and we used more comprehensive and sophisticated outcome measures. We found an association between spectral EEG data and attention performance, suggesting the possibility that spectral characteristics could reflect the activity of early circuitries in the arousal-attentional system, with cascade consequences and persisting effects on the development of attention skills. Our findings may be explained by a failure in the activation of the immature cerebral cortex, reflected by the low content of high-frequency rhythms, from the ascending reticular formation, and the consequent failure of its modulatory activity $[58,59]$. Research on reticular formation's ascending pathways has demonstrated a gating activity, which enables selective attention $[60,61]$ and regulates gaze control as a response to arousing stimulation [62]. Therefore, the reticular activating system is implicated in the regulation of sleep-wake states and the arousal and attention systems. Studies in children born preterm support our hypothesis, reporting sleep-wake dysregulation and difficulties in sustaining and modulating attention and arousal $[63,64]$, orienting behavior [65], alerting [65, 66], and in tasks involving more complex attentional processes such as shifting and divided attention [67-69]. During their permanence in neonatal intensive care units, preterm infants may undergo excessive stimulation from the extra-uterine environment, despite advancements in neonatal care. It is thought that intense and unexpected stimulation such as lights, sounds, smells, and pressure signals incurred at this immature phase of maturation may compromise early formation of the arousal-attention system [70].

The impact of uncomplicated prematurity on cognition may remain latent for several years until more complex functions fail to emergence revealing the underlying neurobiological vulnerability. Complex neuropsychological functions are each other strictly interrelated. The maturation of attention is a prerequisite for the rise of the highest functions, such as flexibility, planning, and inhibition. The attention system allows better coordination of different executive components with an increase of vigilance and sustained attention [71]. After 5 years, the amount and complexity of executive skills 
increase dramatically. In the life of each person, executive functions have a crucial role in adaptive functioning, with consequent effects on quality of life, and recent research indicated executive dysfunctions as the core problem of some psychiatric conditions [72-75]. Furthermore, executive deficits are a frequent report after premature birth [76].

Our findings should be interpreted in light of potential limiting factors. First, the sample size is very small; this long-term longitudinal study requests the need for covering a long period (from the neonatal period to the age when complex cognitive functions develop and can be tested). In 6 years, some patients dropped out or became untraceable. However, given the high effort in the recruitment procedure, the percentage of parents who refused to participate at this stage of the follow-up was very low. Therefore, the majority of lost participants are due to logistic reasons and not the choice of parents, often biased by the effective outcome of their child. Finally, our statistical approach is reliable even with small sample sizes, but, without other confirmatory studies, the small number of patients could limit the generalizability of our results.

Another limit is due to the high number of potential confounding variables that would interact and influence the outcome in the 6 years of the life of the child. For example, we could have investigated parental mental state, known to potentially bias assessment of children's health.

Finally, we selected a group of patients with no evident neurological risk factors other than the prematurity itself. Therefore, our results cannot be generalized to the entire population of preterm infants. However, we were specifically interested in these children in whom the outcome is highly uncertain. In premature infants with evident signs of neurological dysfunctions, the prognosis is relatively simpler. Visual inspections of EEG, MRI, and clinical evaluation may help clinicians in the diagnosis.

\section{Conclusion}

In conclusion, the cumulative effect on the ongoing development of early disruption in cerebral circuitries [77] prompts to early identification of children at risk; results of the present study point to a possible prognostic role of the neonatal EEG spectral analysis also in the challenging group of premature infants in whom the prognosis is particularly difficult because of the absence of overt brain damage. During the time elapsed between the insult and disclosure of impairments, the developmental window for therapeutic interventions may be lost. In early infancy, rehabilitation programs can still favor changes in brain circuitry and on cortical refinement. Currently, it is important to support the achievement of the milestones at the bottom of the subsequent maturation of more complex cognitive abilities. In the absence of interventions, disrupted cerebral circuitries may accumulate during ongoing development, with deleterious cascade effects on subsequent cognitive functioning.

Future research should explore the utility of spectral EEG also in premature neonates with neurological and medical complications.

Authors' contributions Conceptualization: Elisa Cainelli, Luca Vedovelli, Patrizia Silvia Bisiacchi, Agnese Suppiej; Methodology: Luca Vedovelli; Elisa Cainelli; Formal analysis and investigation: Isabella Lucia Chiara Mariani Wigley, Luca Vedovelli, Elisa Cainelli; Writing - original draft preparation: Isabella Lucia Chiara Mariani Wigley; Elisa Cainelli; Writing - review and editing: Patrizia Silvia Bisiacchi, Luca Vedovelli, Agnese Suppiej; Funding acquisition: Patrizia Silvia Bisiacchi; Resources: Agnese Suppiej; Supervision: Patrizia Silvia Bisiacchi, Agnese Suppiej.

Funding Open access funding provided by Università degli Studi di Padova within the CRUI-CARE Agreement. The present work was carried out within the scope of the research program Dipartimenti di Eccellenza (art.1, commi 314-337 legge 232/2016), which was supported by a grant from MIUR to the Department of General Psychology, University of Padua.

\section{Compliance with ethical standards}

Conflict of interest The authors declare that they have no conflict of interest.

Research involving human participants and/or animals This study was performed in line with the principles of the Declaration of Helsinki. Approval was granted by the Ethics Committee "Comitato Etico per la Sperimentazione Clinica dell'Azienda Ospedaliera di Padova, Prot. N. 1693P."

Informed consent Written informed consent was obtained from the parents.

Open Access This article is licensed under a Creative Commons Attribution 4.0 International License, which permits use, sharing, adaptation, distribution and reproduction in any medium or format, as long as you give appropriate credit to the original author(s) and the source, provide a link to the Creative Commons licence, and indicate if changes were made. The images or other third party material in this article are included in the article's Creative Commons licence, unless indicated otherwise in a credit line to the material. If material is not included in the article's Creative Commons licence and your intended use is not permitted by statutory regulation or exceeds the permitted use, you will need to obtain permission directly from the copyright holder. To view a copy of this licence, visit http://creativecommons.org/licenses/by/4.0/.

\section{References}

1. He L, Li H, Holland SK, Yuan W, Altaye M, Parikh NA (2018) Early prediction of cognitive deficits in very preterm infants using functional connectome data in an artificial neural network framework. NeuroImage Clin 18:290-297. https://doi.org/10.1016/j.nicl. 2018.01.032

2. Jarjour IT (2015) Neurodevelopmental outcome after extreme prematurity: a review of the literature. Pediatr Neurol 52:143-152. https://doi.org/10.1016/j.pediatrneurol.2014.10.027 
3. Marlow N, Wolke D, Bracewell MA, Samara M (2005) Neurologic and developmental disability at six years of age after extremely preterm birth. N Engl J Med 352:9-19. https://doi.org/10.1056/ NEJMoa041367

4. Beckwith L, Parmelee AH (1986) EEG patterns of preterm infants, home environment, and later IQ. Child Dev 57:777-789. https:// doi.org/10.1111/j.1467-8624.1986.tb00245.x

5. Saigal S, Doyle LW (2008) An overview of mortality and sequelae of preterm birth from infancy to adulthood. Lancet 371:261-269. https://doi.org/10.1016/S0140-6736(08)60136-1

6. Volpe JJ (2009) Brain injury in premature infants: a complex amalgam of destructive and developmental disturbances. Lancet Neurol 8:110-124. https://doi.org/10.1016/S1474-4422(08)70294-1

7. Larroque B, Ancel PY, Marret S, Marchand L, André M, Arnaud C, Pierrat V, Rozé JC, Messer J, Thiriez G, Burguet A, Picaud JC, Bréart G, Kaminski M (2008) Neurodevelopmental disabilities and special care of 5-year-old children born before 33 weeks of gestation (the EPIPAGE study): a longitudinal cohort study. Lancet 371: 813-820. https://doi.org/10.1016/S0140-6736(08)60380-3

8. Perlman JM (2003) The genesis of cognitive and behavioral deficits in premature graduates of intensive care. Minerva Pediatr 55:89101

9. Caravale B, Mirante N, Vagnoni C, Vicari S (2012) Change in cognitive abilities over time during preschool age in low risk preterm children. Early Hum Dev 88:363-367. https://doi.org/10. 1016/j.earlhumdev.2011.09.011

10. Mürner-Lavanchy I, Ritter BC, Spencer-Smith MM, Perrig WJ, Schroth G, Steinlin M, Everts R (2014) Visuospatial working memory in very preterm and term born children - impact of age and performance. Dev Cogn Neurosci 9:106-116. https://doi.org/10. 1016/j.dcn.2014.02.004

11. Baron IS, Erickson K, Ahronovich MD, Baker R, Litman FR (2011) Neuropsychological and behavioral outcomes of extremely low birth weight at age three. Dev Neuropsychol 36:5-21. https:// doi.org/10.1080/87565641.2011.540526

12. Orchinik LJ, Taylor HG, Espy KA, Minich N, Klein N, Sheffield T, Hack M (2011) Cognitive outcomes for extremely preterm/ extremely low birth weight children in kindergarten. J Int Neuropsychol Soc 17:1067-1079. https://doi.org/10.1017/ S135561771100107X

13. De Kieviet JF, Van Elburg RM, Lafeber HN, Oosterlaan J (2012) Attention problems of very preterm children compared with agematched term controls at school-age. J Pediatr 161:824-829. https:// doi.org/10.1016/j.jpeds.2012.05.010

14. Murray AL, Thompson DK, Pascoe L, Leemans A, Inder TE, Doyle LW, Anderson JFI, Anderson PJ (2016) White matter abnormalities and impaired attention abilities in children born very preterm. Neuroimage 124:75-84. https://doi.org/10.1016/j. neuroimage.2015.08.044

15. Cainelli E, Arrigoni F, Vedovelli L (2020) White matter injury and neurodevelopmental disabilities: a cross-disease (dis)connection. Prog Neurobiol 193:101845. https://doi.org/10.1016/j.pneurobio. 2020.101845

16. Johnson S, Wolke D (2013) Behavioural outcomes and psychopathology during adolescence. Early Hum Dev 89:199-207. https:// doi.org/10.1016/j.earlhumdev.2013.01.014

17. Hack M, Taylor HG, Drotar D, Schluchter M, Cartar L, WilsonCostello D, Klein N, Friedman H, Mercuri-Minich N, Morrow M (2005) Poor predictive validity of the Bayley Scales of infant development for cognitive function of extremely low birth weight children at school age. Pediatrics 116:333-341. https://doi.org/10. 1542/peds.2005-0173

18. Ment LR, Vohr B, Allan W, Katz KH, Schneider KC, Westerveld M, Duncan CC, Makuch RW (2003) Change in cognitive function over time in very low-birth-weight infants. J Am Med Assoc 289: 705-711. https://doi.org/10.1001/jama.289.6.705
19. Spencer-Smith MM, Spittle AJ, Lee KJ, Doyle LW, Anderson PJ (2015) Bayley-III cognitive and language scales in preterm children. Pediatrics 135:e1258-e1265. https://doi.org/10.1542/peds. 2014-3039

20. Linsell L, Johnson S, Wolke D, O'Reilly H, Morris JK, Kurinczuk JJ, Marlow N (2018) Cognitive trajectories from infancy to early adulthood following birth before 26 weeks of gestation: a prospective, population-based cohort study. Arch Dis Child 103:363-370. https://doi.org/10.1136/archdischild-2017-313414

21. Atladóttir HÓ, Parner ET, Schendel D, et al (2007) Time trends in reported diagnoses of childhood neuropsychiatric disorders: a Danish cohort study. In: Arch. Pediatr. Adolesc. Med. http:// archpedi.jamanetwork.com/article.aspx?doi=10.1001/archpedi. 161.2.193. Accessed 1 Nov 2018

22. Thomason ME, Grove LE, Lozon TA et al (2015) Age-related increases in long-range connectivity in fetal functional neural connectivity networks in utero. Dev Cogn Neurosci 11:96-104. https:// doi.org/10.1016/j.den.2014.09.001

23. Toulmin H, Beckmann CF, O'Muircheartaigh J et al (2015) Specialization and integration of functional thalamocortical connectivity in the human infant. Proc Natl Acad Sci U S A 112: 6485-6490. https://doi.org/10.1073/pnas.1422638112

24. Wheelock MD, Austin NC, Bora S, Eggebrecht AT, Melzer TR, Woodward LJ, Smyser CD (2018) Altered functional network connectivity relates to motor development in children born very preterm. Neuroimage 183:574-583. https://doi.org/10.1016/j. neuroimage.2018.08.051

25. Suppiej A, Cainelli E, Cappellari A, Ermani M, Sartori S, Bisiacchi PS (2015) Neonatal cortical auditory evoked potentials are affected by clinical conditions occurring in early prematurity. J Clin Neurophysiol 32:419-423. https://doi.org/10.1097/WNP. 0000000000000182

26. Bisiacchi PS, Mento G, Suppiej A (2009) Cortical auditory processing in preterm newborns: an ERP study. Biol Psychol 82:176-185. https://doi.org/10.1016/j.biopsycho.2009.07.005

27. Suppiej A, Mento G, Zanardo V, Franzoi M, Battistella PA, Ermani M, Bisiacchi PS (2010) Auditory processing during sleep in preterm infants: an event related potential study. Early Hum Dev 86: 807-812. https://doi.org/10.1016/j.earlhumdev.2010.09.002

28. Suppiej A, Cainelli E, Cappellari A, Trevisanuto D, Balao L, di Bono MG, Bisiacchi PS (2017) Spectral analysis highlight developmental EEG changes in preterm infants without overt brain damage. Neurosci Lett 649:112-115. https://doi.org/10.1016/j.neulet. 2017.04.021

29. Cainelli E, Di Bono MG, Bisiacchi PS, Suppiej A (2020) Electroencephalographic functional connectivity in extreme prematurity: a pilot study based on graph theory. Pediatr Res 87: 753-759. https://doi.org/10.1038/s41390-019-0621-3

30. Suppiej A, Festa I, Bartolini L, Cappellari A, Cainelli E, Ermani M, Trevisanuto D (2014) Power spectral analysis of two-channel EEG in very premature infants undergoing heat loss prevention. Neurophysiol Clin 44:239-244. https://doi.org/10.1016/j.neucli. 2014.07.001

31. Brito NH, Fifer WP, Myers MM, Elliott AJ, Noble KG (2016) Associations among family socioeconomic status, EEG power at birth, and cognitive skills during infancy. Dev Cogn Neurosci 19: 144-151. https://doi.org/10.1016/j.den.2016.03.004

32. Richards JE, Parmelee AH, Beckwith L (1986) Spectral analysis of infant EEG and behavioral outcome at age five. Electroencephalogr Clin Neurophysiol 64:1-11. https://doi.org/10.1016/0013-4694(86) 90037-4

33. Kostović I, Judaš M (2006) Prolonged coexistence of transient and permanent circuitry elements in the developing cerebral cortex of fetuses and preterm infants. Dev Med Child Neurol 48:388-393 
34. Blackmon LR, Batton DG, Bell EF et al (2004) Age terminology during the perinatal period. Pediatrics 114:1362-1364. https://doi. org/10.1542/peds.2004-1915

35. Steriade M, Gloor P, Llinás RR, Lopes da Silva FH, Mesulam MM (1990) Report of IFCN Committee on Basic Mechanisms. Basic mechanisms of cerebral rhythmic activities. Electroencephalogr Clin Neurophysiol 76:481-508

36. Orsini A, Pezzuti L, Picone L (2011) WISC-IV. Contributo alla taratura Italiana [WISC-IV Italian Edition]. Giunti O.S. Organizzazioni Speciali, Firenze

37. Wechsler D (2003) Wechsler intelligence scale for children. 4. The Psychological Corporation, San Antonio, TX

38. Wechsler D (2002) Wechsler preschool and primary scale of intelligence - third edition: Canadian. Pearson Clinical Assessment Canada, Toronto, ON

39. Bisiacchi P, Cendron M, Gugliotta M, et al (2005) BVN. Batteria di Valutazione Neuropsicologica per l'Età Evolutiva. Trento

40. Korkman M, Kirk U, Kemp S (2007) NEPSY-II: a developmental neuropsychological assessment, 2nd ed. Psychological Corporation, San Antonio

41. Urgesi C, Campanella F, Fabbro F (2011) NEPSY-II. Second edition. Contributo alla taratura italiana. Giunti O.S. Organizzazioni Speciali, Firenze

42. Sannio Facello G, Vio C, Cianchetti C (2006) TOL Torre di Londra, test ti valutazione delle funzioni esecutive (pianificazione e problem solving). Erickson, Trento

43. Marzocchi G, Re A, Cornoldi C (2010) BIA - Batteria italiana per l'ADHD per la valutazione dei bambini con deficit di attenzione/ iperattività. Erickson, Trento

44. Beery KE, Beery NA (2004) The Beery-Buktenica developmental test of visual motor integration: administration, scoring, and teaching manual (5th edition), 5th ed. Modern Curriculum Press, Cleveland

45. Conners C (2000) Conners' rating scales-revised. Multi-Health Systems, New York

46. Lange K, Sinsheimer JS (1993) Normal/independent distributions and their applications in robust regression. J Comput Graph Stat 2: 175-198. https://doi.org/10.1080/10618600.1993.10474606

47. Gelman A, Simpson D, Betancourt M (2017) The prior can often only be understood in the context of the likelihood. Entropy 19:555. https://doi.org/10.3390/e19100555

48. Gabry J, Simpson D, Vehtari A, Betancourt M, Gelman A (2019) Visualization in Bayesian workflow. J R Stat Soc Ser A Stat Soc 182:389-402. https://doi.org/10.1111/rssa.12378

49. Lewandowski D, Kurowicka D, Joe H (2009) Generating random correlation matrices based on vines and extended onion method. J Multivar Anal 100:1989-2001. https://doi.org/10.1016/j.jmva. 2009.04.008

50. Carpenter B, Gelman A, Hoffman MD et al (2017) Stan: a probabilistic programming language. J Stat Softw 76:1-32. https://doi. org/10.18637/jss.v076.i01

51. Gelman A, Carlin JB, Tern HS, et al (2013) Bayesan data analysis Third edition. Chapman and Hall/CRC

52. R Core Team (2020) The R project for statistical computing. R Foundation for Statistical Computing, Vienna

53. Bürkner PC (2017) brms: an R package for Bayesian multilevel models using Stan. J Stat Softw 80. https://doi.org/10.18637/jss. v080.i01

54. Suppiej A, Cappellari A, Cainelli E (2012) Clinical neurophysiology in preterm infants: a window on early phases of brain development. In: Pediatric Neurology. Nova Publisher, pp. 115-130
55. Penn AA, Shatz CJ (1999) Brain waves and brain wiring: the role of endogenous and sensory-driven neural activity in development. Pediatr Res 45:447-458. https://doi.org/10.1203/00006450199904010-00001

56. Vanhatalo S, Kaila K (2006) Development of neonatal EEG activity: from phenomenology to physiology. Semin Fetal Neonatal Med 11:471-478. https://doi.org/10.1016/j.siny.2006.07.008

57. Vecchierini MF, André M, d'Allest AM (2007) Normal EEG of premature infants born between 24 and 30 weeks gestational age: terminology, definitions and maturation aspects. Neurophysiol Clin 37:311-323. https://doi.org/10.1016/j.neucli.2007.10.008

58. Kropotov JD (2009) Quantitative EEG, event-related potentials and neurotherapy, 1st ed. Academic Press - Elsevier

59. Moruzzi G, Magoun HW (1995) Brain stem reticular formation and activation of the EEG. 1949. J Neuropsychiatr Clin Neurosci 7: 251-267. https://doi.org/10.1176/jnp.7.2.251

60. Kinomura S, Larsson J, Gulyás B, Roland PE (1996) Activation by attention of the human reticular formation and thalamic intralaminar nuclei. Science (80- ) 271:512-515. https://doi.org/10.1126/ science. 271.5248 .512

61. Schiff ND, Plum F (2000) The role of arousal and "gating" systems in the neurology of impaired consciousness. J Clin Neurophysiol 17:438-452. https://doi.org/10.1097/00004691-200009000-00002

62. Perkins E, Warren S, May PJ (2009) The mesencephalic reticular formation as a conduit for primate coliicular gaze control: tectalinputs to neurons targeting the spinal cord and medulla. Anat Rec 292:1162-1181. https://doi.org/10.1002/ar.20935

63. Geva R, Gardner JM, Karmel BZ (1999) Feeding-based arousal effects on visual recognition memory in early infancy. Dev Psychol 35:640-650. https://doi.org/10.1037/0012-1649.35.3.640

64. Richards JE (1994) Baseline respiratory sinus arrhythmia and heart rate responses during sustained visual attention in preterm infants from 3 to 6 months of age. Psychophysiology 31:235-243

65. van de Weijer-Bergsma E, Wijnroks L, Jongmans MJ (2008) Attention development in infants and preschool children born preterm: a review. Infant Behav Dev 31:333-351. https://doi.org/10. 1016/j.infbeh.2007.12.003

66. Mulder H, Pitchford NJ, Hagger MS, Marlow N (2009) Development of executive function and attention in preterm children: a systematic review. Dev Neuropsychol 34:393-421. https:// doi.org/10.1080/87565640902964524

67. Bayless S, Stevenson J (2007) Executive functions in school-age children born very prematurely. Early Hum Dev 83:247-254. https://doi.org/10.1016/j.earlhumdev.2006.05.021

68. Mulder H, Pitchford NJ, Marlow N (2011) Processing speed mediates executive function difficulties in very preterm children in middle childhood. J Int Neuropsychol Soc 17:445-454. https://doi.org/ 10.1017/S1355617711000373

69. Murray AL, Scratch SE, Thompson DK, Inder TE, Doyle LW, Anderson JFI, Anderson PJ (2014) Neonatal brain pathology predicts adverse attention and processing speed outcomes in very preterm and/or very low birth weight children. Neuropsychology 28 : 552-562. https://doi.org/10.1037/neu0000071

70. Geva R, Yaron H, Kuint J (2016) Neonatal sleep predicts attention orienting and distractibility. J Atten Disord 20:138-150. https://doi. org $/ 10.1177 / 1087054713491493$

71. Garon N, Bryson SE, Smith IM (2008) Executive function in preschoolers: a review using an integrative framework. Psychol Bull 134:31-60. https://doi.org/10.1037/0033-2909.134.1.31

72. Cainelli E, Nosadini M, Sartori S, Suppiej A (2019) Neuropsychological and psychopathological profile of antiNMDAR encephalitis: a possible pathophysiological model for 
pediatric neuropsychiatric disorders. Arch Clin Neuropsychol 34: 1309-1319. https://doi.org/10.1093/arclin/acy088

73. Bünger A, Urfer-Maurer N, Grob A (2019) Multimethod assessment of attention, executive functions, and motor skills in children with and without ADHD: children's performance and parents' perceptions. J Atten Disord 108705471882498:108705471882498. https://doi.org/10.1177/1087054718824985

74. Penadés R, Catalán R, Rubia K, Andrés S, Salamero M, Gastó C (2007) Impaired response inhibition in obsessive compulsive disorder. Eur Psychiatry 22:404 410. https://doi.org/10.1016/j.eurpsy. 2006.05.001

75. Reynolds BW, Basso MR, Miller AK, Whiteside DM, Combs D (2019) Executive function, impulsivity, and risky behaviors in young adults. Neuropsychology 33:212-221. https://doi.org/10. $1037 /$ neu0000510
76. Kalpakidou AK, Allin MPG, Walshe M, Giampietro V, McGuire PK, Rifkin L, Murray RM, Nosarti C (2014) Functional neuroanatomy of executive function after neonatal brain injury in adults who were born very preterm. PLoS One 9:e113975. https://doi.org/10. 1371/journal.pone.0113975

77. Aarsen FK, Paquier PF, Reddingius RE, Streng IC, Arts WFM, Evera-Preesman M, Catsman-Berrevoets CE (2006) Functional outcome after low-grade astrocytoma treatment in childhood. Cancer 106:396-402. https://doi.org/10.1002/cncr.21612

Publisher's note Springer Nature remains neutral with regard to jurisdictional claims in published maps and institutional affiliations. 